\title{
Growth and yield prediction of Indian mustard using InfoCrop model at Hisar, Haryana
}

\author{
P. KEERTHI*, RAJ SINGH, A. K.DHAKA and C. DIVESH \\ Department of Agronomy, College of Agriculture, CCS Haryana Agricultural University, Hisar-125004 \\ *corresponding author: sharmakittu26@gmail.com
}

\begin{abstract}
ABSTARCT
The InfoCrop v.2.0, model was calibrated and validated with the field experimental data having four dates of sowing (Oct $15^{\text {th }} \& 25^{\text {th }}$ and Nov $\left.5^{\text {th }} \& 15^{\text {th }}\right)$ and five nitrogen levels $(0,40,60,80$ and $100 \mathrm{~kg}$ $\left.\mathrm{N} \mathrm{ha}^{-1}\right)$ conducted during $2013-15$ at Hisar $\left(29^{\circ} 10 \mathrm{E} \mathrm{N}\right.$ and $\left.75^{\circ} 46 \mathrm{E} \mathrm{E}\right)$. The model performance was evaluated using RMSE, MAE and MBE and it was observed that InfoCrop model could predict the growth parameters leaf area index, nitrogen uptake, biomass and seed yield with reasonably good accuracy.
\end{abstract}

Keywords: InfoCrop, calibration, Indian mustard, dates of sowing and nitrogen levels.

Crop simulation models (CSM) have been used extensively in India to quantify the change in yield potential at different levels of management and climatic variability. InfoCrop is a generic, dynamic crop yield simulation model with sensitivity to variety, agronomic management, soil, weather, flooding, frost and pests (Aggarwal et al., 2006). The model has been earlier validated for its performance across varying climates, soils and management conditions at the field level. This model has the capability of analysis of experimental data, estimate the potential yield and yield gaps and also to assess the impacts of climate variability and climate change. The scientific information on crop growth modeling under different growing conditions on mustard crop in Haryana state is limited. Hence, keeping all these points in view, the present investigation was undertaken.

\section{MATERIALS AND METHODS}

Field experiments were conducted at Hisar (Lat.29 $10^{\prime} \mathrm{N}$ and Long. $75^{\circ} 46^{\prime} \mathrm{E}$ ) during rabi seasons of 2013-14 and 2014-15 on mustard crop cv. RH 0749 with treatments comprising of four dates of sowing (October 15, 25 and November 5 and 15) and five nitrogen levels $(0,40,60,80$ and $\left.100 \mathrm{~kg} \mathrm{~N} \mathrm{ha}^{-1}\right)$. The daily meteorological data during experimental periods were recorded at the agrometeorological observatory located near to the Research Farm of Chaudary Charan Singh Haryana Agricultural University, Hisar.

The general structure and details of the InfoCrop series of models are described byAggarwal et al. (2004). The InfoCrop model requires daily weather data of maximum and minimum air temperature (ÚC), solar radiation $\left(\mathrm{k} \mathrm{Jm}^{-2} \mathrm{~d}^{-1}\right)$, vapour pressure $(\mathrm{kPa})$, wind speed $\left(\mathrm{ms}^{-1}\right)$ and rainfall $(\mathrm{mm})$.
Calibration of model involves adjusting certain model parameters or relationships to make the model work for any desired location. The model requires cultivar specific genetic coefficients. The details of these coefficients are given in Table 1. For calibration of InfoCrop model one year (201314) data set was used and for validation, data sets of 2014 15 experiments were used. Validation of model was done by using data sets on phenology, leaf area index, biomass, seed yield and nitrogen uptake from experiments conducted at Research Farm Hisar.

For judging the performance of the InfoCrop model, the simulated data were tested using statistical parameters viz., mean absolute error (MAE), mean bias error (MBE) and root mean square error (RMSE), and error per cent.

$$
\begin{aligned}
& \text { MAE }=\sum_{i=1}^{n}\left[1 P_{i}-O_{i} 1\right] / n \\
& \operatorname{MBE}=\sum_{i=1}^{n}\left[P_{i}-O_{i}\right] / n \\
& \operatorname{RMSE}=\left[\sum_{i=1}^{n}\left(P_{i}-O_{i}\right)^{2} / n\right]^{1 / 2} \\
& \text { Error }(\%)=\{(P-O) / O\} * 100
\end{aligned}
$$

Where, $\mathrm{O}=$ observed, $\mathrm{P}=$ simulated, $\mathrm{n}=$ no. of treatments

\section{RESULTS AND DISCUSSION}

\section{Leaf area index at maturity}

The observed leaf area index (LAI) and simulated LAI by the InfoCrop model (Fig 1) shows that the model slightly underestimated the LAI. The calculated values of statistical indices, such as RMSE, MAE, MBE were 0.05, 0.04, and 0.03 respectively. The very low values suggest that the 
Table 1: Genetic coefficient of mustard cv. RH0749 for InfoCrop v.2.0 model

Genetic constant description Unit

\section{A.Phenology}

Thermal time for germination to emergence

Thermal time for seedling emergence to anthesis

Thermal time for anthesis to maturity

Optimum temperature

Maximum temperature

Sensitivity to photoperiod

\section{B. Growth}

Relative growth rate

Specific leaf area of variety

Index of greenness of leaves

Extinction coefficient of leaves at flowering

Radiation use efficiency

Root growth rate

Sensitivity of crop to flooding

Index of nitrogen fixation

\section{Source :Sink relation}

Maximum number of grains per hectare

Potential storage organ weight

Nitrogen content of storage organ

Sensitivity of storage organ setting to low temperature

Sensitivity of storage organ setting to high temperature

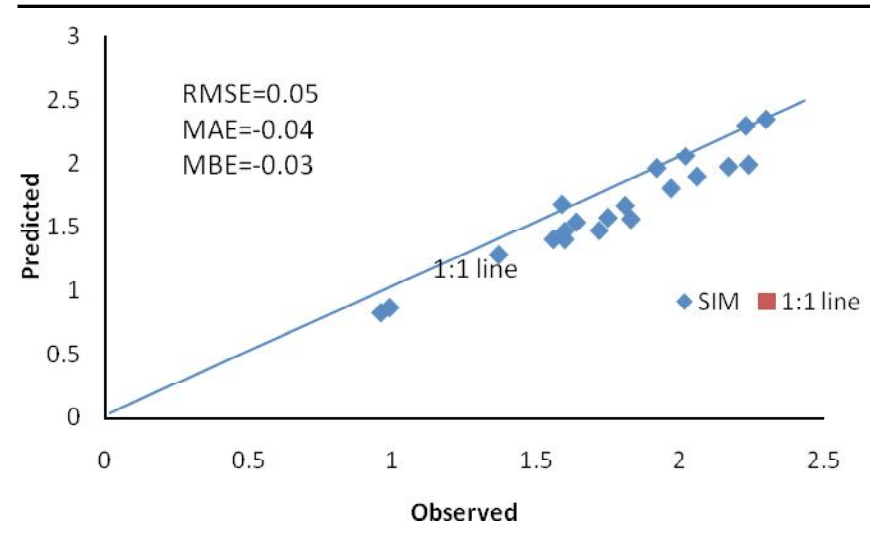

Fig1: Observed and simulated LAI of mustard at Hisar.

model can be used for simulating the LAI. Neog et al. (2006.) and Adak et al. (2009) also reported that the InfoCrop model underestimated the LAI at maturity under the accepted range of error percentage.
Values

$\begin{array}{ll}\left({ }^{\circ} \mathrm{C} \text { day }\right) & 120 \\ \left({ }^{\circ} \mathrm{C} \text { day }\right) & 920 \\ \left({ }^{\circ} \mathrm{C} \text { day }\right) & 1140 \\ \left({ }^{\circ} \mathrm{C}\right) & 20 \\ \left({ }^{\circ} \mathrm{C}\right) & 35 \\ - & 1\end{array}$

(ÚC day $\left.{ }^{-1}\right) \quad 0.008$

$\left(\mathrm{dm}^{2} \mathrm{mg}^{-1)} \quad 0.0024\right.$

$-1$

- $\quad 0.6$

$\left(\mathrm{g} \mathrm{MJ}^{-1}\right.$ day $\left.^{-1}\right) \quad 2.26$

$\left(\mathrm{mm} \mathrm{day}^{-1}\right) \quad 48$

- 1

$-$

grains perhectare $\quad 4465700$

$\mathrm{mg} /$ grain $\quad 6.07$

fraction $\quad 0.039$

$\mathrm{mm} / \mathrm{d}$

$\mathrm{mm} / \mathrm{d} \quad 1$

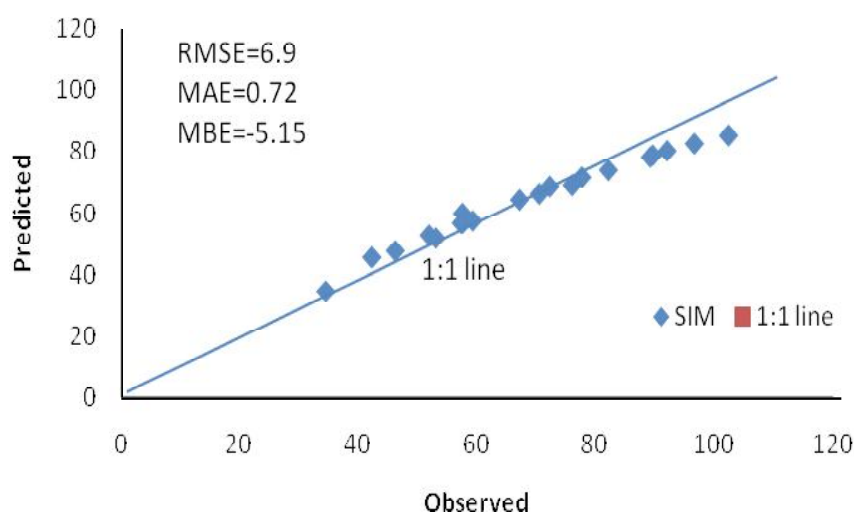

Fig2: Observed and simulated nitrogen uptake $\left(\mathrm{kgha}^{-1}\right)$ of mustard at Hisar.

\section{Nitrogen uptake ( $\left.\mathrm{kg} \mathrm{ha}^{-1}\right)$}

The observed total nitrogen uptake and simulated by the model (Fig 2) shows that the model simulated total nitrogen uptake accurately with slight underestimation in almost all the treatments. The RMSE, MAE, MBE between 


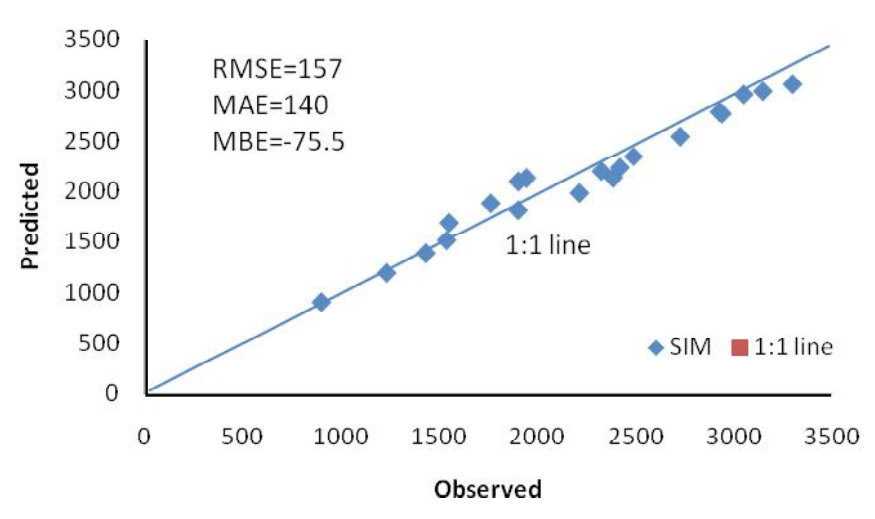

Fig. 3: Observed and simulated seed yield $\left(\mathrm{kgha}^{-1}\right)$ of mustard at Hisar.

observed and predicted were $6.91,0.72$, and -5.15 respectively which are under acceptable limit. Hence model can also be used to simulate nitrogen uptake of mustard crop.

\section{Seed yield $\left(\mathrm{kg} \mathrm{ha}^{-1}\right)$}

The observed and simulated seed yield $\left(\mathrm{kg} \mathrm{ha}^{-1}\right)$ of Indian mustard revealed that the model simulated the seed yield accurately, the slight under estimation was within the acceptable range of error percentage (Fig. 3). The RMSE,MAE and MBE were 157,140.2 and -75.5 respectively for all the dates of sowing suggested that model can be used for predicting seed yield.

\section{Biomass at maturity ( $\left.\mathrm{kg} \mathrm{ha}^{-1}\right)$}

Data pertaining to biomass yield $\left(\mathrm{kg} \mathrm{ha}^{-1}\right)$ revealed that the model underestimated the biomass yield (Fig. 4). The model simulated the biological yield all more accurately as evident from the acceptable range of statistical indices, such as RMSE, MAE and MBE were 1364, 1168 and -966.3 respectively.

\section{CONCLUSION}

InfoCrop model validated for mustard ev RH0749 can

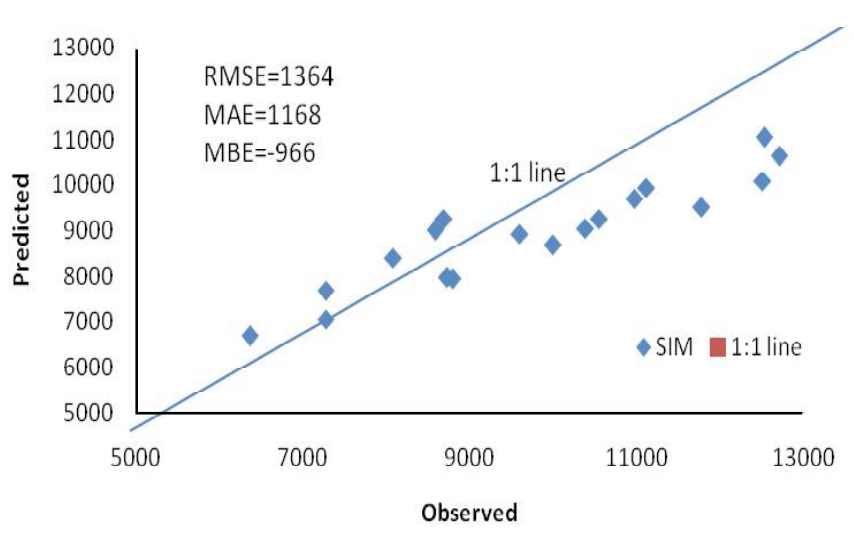

Fig.4: Observed and simulated biomass $\left(\mathrm{kgha}^{-1}\right)$ of mustard at Hisar.

be used for predicting the seed yield, biomass and total nitrogen uptake under different dates of sowing and nitrogen levels.

\section{REFERENCES}

Adak T., Chakravarty, N. V.K. \& Rani, S. (2009). Growth and yield prediction in mustard using InfoCrop simulation model.J.Agrometeorol., 11(2): 156-161.

Aggarwal, P.K., Kalra, N., Chander, S. \& Pathak, H. (2004). InfoCrop: Ageneric simulation model for annual crops in tropical environments. Indian Agricultural research Institutes, New Delhi, and P.132.

Aggarwal, P.K., Kalra, N., Chander, S. \& Pathak, H. (2006). Infocrop:Adynamic simulation model for the assessment of crop yields, losses due to pests, and environmental impact of agro-ecosystems in tropical environments. I. Performance of the model. Agric. Syst., 89: 47-67

Neog, P., Ckakravarthy, N.V.K., andSrivastava, A.K. (2006). Parameterization and validation of BRASSICA model for Brassica junceain semi arid environment. $J$. Agrometeorol., 8: 174-178. 